\title{
Perfect foresight portfolios on the Johannesburg stock exchange
}

\author{
R. van der Merwe and J.D. Krige* \\ Stellenbosch University, Private Bag X1, Matieland, 7602 \\ *To whom all correspondence should be addressed \\ jdkrige@sun.ac.za
}

\begin{abstract}
The main aim of this study was to determine the effect of unanticipated information, or noise, on the returns of cap-weighted portfolios in various segments of the JSE for the period 1995 to 2014.

According to Fuller, Han and Tung (2012), all investors in a segment would gain maximum alpha from a portfolio weighted by ex post market capitalisation - in other words, a 'perfect foresight' (PF) portfolio. The PF portfolio is a buy-and-hold portfolio of all shares in a particular segment with weights at the beginning of the return period set to be proportional to the market capitalisation of the shares at the end of the return period. The excess return of the PF portfolio over the benchmark portfolio therefore is an estimate of the effect of unanticipated information on the return of the benchmark portfolio. It provides an estimate of the maximum annual amount of available alpha to all investors involved in that segment in a given year. In this study, the returns of PF portfolios were compared with the All Share, Large Cap, Mid Cap and Small Cap segments of the JSE.
\end{abstract}

\begin{abstract}
Intuitively, information to guide decisions on portfolio weighting would be more valuable and deliver more profit when the cross-sectional standard deviation of share returns is high. Therefore a secondary aim was to investigate the correlation between cross-sectional standard deviation and PF excess return. It was found that a strong positive correlation (more than 90\%) existed between cross-sectional standard deviation and PF excess return in all segments.
\end{abstract}

In ascending order of annual PF excess return and average cross-sectional standard deviation the results for the segments were: Large Cap (8\% and 29\%), All Share (9\% and 32\%), Mid Cap (13\% and 36\%) and Small Cap (17\% and 43\%).

\section{Introduction}

The Capital Asset Pricing Model (CAPM) states that the optimal risky portfolio consists of all the shares in a segment weighted by market capitalisation. Its elegant simplicity and promise of optimal risk-return benefit inspired a generation of investors to choose index tracking as an investment approach, but this approach is a strategy to match the market, not to beat it.

Active investment management, on the other hand, is aimed at outperforming the market. Active managers seek alpha by deviating from market capitalisation and creating portfolios that are overweight in shares they believe will become 'winner' shares and underweight in shares they believe will become 'loser' shares. The performance (ex post returns) of active managers is often measured against the cap-weighted benchmark portfolio.

This study investigated 'valuation' efficiency in capweighted JSE segments. Share prices reflect the market's consensus expectations of future value, but realised future value rarely equals expected value, because unanticipated information causes unexpected price changes during the investment period.
The primary aim of this study was to determine the effect of unanticipated information on the returns of cap-weighted portfolios for the main segments of the JSE. The study included the All Share, Top 40, Mid Cap and Small Cap segments for the period 1995 to 2014 . Not only are these indices popular with investors, but they are also common benchmarks for active management.

Intuitively, unanticipated information and a high dispersion of annual share returns should provide active investors with more profitmaking opportunities. Therefore a secondary aim was to investigate the correlation between excess returns and cross-sectional standard deviation.

The methodology used in this study is based on the one developed by Fuller, Han and Tung (2012). They used CAPM and the concept of 'perfect foresight' (PF) to estimate the effect of unanticipated information on the returns of capweighted portfolios.

Although individual investors in a segment can hold portfolios consisting of any shares in any quantity, they collectively hold all shares in the segment weighted by market capitalisation. The ex ante cap-weighted portfolio, consisting of all shares in a segment, is an optimal portfolio that lies on the ex ante efficient frontier. It represents the market's consensus expectations of returns in the segment. If 
estimates of future value are $100 \%$ accurate, the ex ante market portfolio would also lie on the ex post efficient frontier. It is however an improbable scenario as some level of ex ante mispricing always exists due to information unavailable and unanticipated at $\mathrm{t}=0$. The ex ante market portfolio therefore tends to be overweight in 'loser' shares, or shares that will not achieve their expected return, and underweight in 'winner' shares, or shares that will exceed their expected return. These 'winner' and 'loser' shares are created when prices change unexpectedly during the investment period. Noise is the array of factors causing unexpected price changes. It includes rational behaviour such as the correction of ex ante mispricing and market reaction to new information, as well as irrational investor behaviour.

Fuller et al. (2012) defined the PF portfolio as the portfolio that investors in the segment would have chosen, as a group, had they had PF about price changes caused by noise during the investment period. The PF portfolio consists of the same shares as the benchmark portfolio, but is weighted by ex post market capitalisation and lies on the ex post efficient frontier. The PF portfolio therefore is a buy-and-hold portfolio of all shares in a particular segment with weights at the beginning of the return period set to be proportional to the market capitalisation of the shares at the end of the return period.

If accepted as a valid estimate of the maximum potential alpha across all investors in a segment, PF excess return could serve as a useful benchmark in the evaluation of active managers' goals, performance and reward. If the PF excess return is only $1 \%$, it is unlikely that active managers will beat the segment benchmark for that period. A larger difference, say $20 \%$, would significantly increase the probability for an active manager to outperform the benchmark (Fuller et al., 2012). Finally, when maximum potential alpha is 5\%, should one expect superior active managers in the segment to earn half of it, say $2 \%$ to $3 \%$ (Fuller et al., 2012)?

This study is organised as follows. Section 2 consists of a literature review which includes a description of factors causing inefficiencies in the market. Section 3 provides a description of the data required for the study and the specific methodology employed. Section 4 reports and analyses the findings of the study. It starts with a detailed description of the findings for the All Share segment, followed by summarised result sets and descriptions for the other segments. In conclusion, Section 5 provides a summary of the main findings, a description of the limitations of the study, as well as recommendations for future research.

\section{Literature review}

De Long, Shleifer, Summers and Waldmann (1990) defined 'noise traders' as investors who do not act rationally according to Modern Portfolio Theory. These unsophisticated investors may be unaware of or misunderstand the link between fundamental value and share price. They often pick shares based on hunches, systems, flawed personal research or the irrational advice of brokers, investment journals and investor clubs. In addition, they fail to diversify and hold a single share or a small number of shares (Lewellen, Schlarbaum \& Lease, 1974).

Although the abundance of noise traders has historically been recognised, it was thought that their effect on share prices was neutralised by rational investors who traded against them to exploit arbitrage opportunities and, in the process, drove prices close to fundamental values (Fama,1965). Irrational noise traders were expected to lose money in the long term and eventually disappear from the market. Shiller, Fischer and Friedman (1984), and Campbell and Kyle (1993) found however that rational investors were averse to the risk that noise trader opinions may cause prices to change even further from fundamental values and therefore chose not to trade against them, especially in the short run. De Long et al. (1990) also found that the unpredictability of unsophisticated investors' opinions significantly reduced the attractiveness of arbitrage. As long as rational arbitrageurs have short horizons and worry about liquidating their investments in mispriced assets, their aggressiveness is limited even in the absence of fundamental risk. Irrational noise trading can therefore lead to large differences between fundamental values and market prices.

Black (1986) agreed that irrational traders contributed to noise in financial markets, but defined noise much wider than De Long et al. (1990) did. According to Black (1986), noise is an array of unrelated factors that cause investor observations to be imperfect. He argued that, if information is the only cause for trade, investors will hold individual assets but will trade only rarely to manage their exposure to market risk. An investor may want to trade on information received, but will struggle to find a counterparty to his trade if all other market participants hold well diversified portfolios and have exactly the same insight. If there is a trade, one of the parties must be making a mistake and, if those making mistakes decline to trade, there will be no trading on information and financial markets would not 'work'. Financial markets therefore depend on investors who interpret information differently or incorrectly and make mistakes. Investors use noise as if it was information and trade, even when it does not make rational sense to do so. Noise causes share prices to stray from theoretical values and realised returns to differ from expected returns (Black, 1986).

Similar to Black (1986), Fuller et al. (2012) defined noise as all factors that cause prices to change unexpectedly during an investment period. To estimate the effect of noise on the returns of cap-weighted market portfolios, Fuller et al. (2012) used CAPM and the concept of PF. Their definition of PF was similar in spirit, but empirically different to Shiller (1979 \& 1981), LeRoy and LaCivita (1981), and Arnott, Li and Sherrerd (2009), because Fuller et al. (2012) applied the concept of PF to the weighting of ex ante market portfolios rather than share price or value.

Although individual investors can construct portfolios as they prefer, Fuller et al. (2012) assumed that all investors in the market would construct an aggregate portfolio weighted by ex post market capitalisation if they had PF. Fuller et al. 's (2012) PF portfolio therefore consisted of exactly the same 
shares as the benchmark portfolio, but the PF portfolio was weighted by market capitalisation at the end of the investment period $(\mathrm{t}=1)$ whereas the benchmark portfolio was weighted by market capitalisation at the start of the investment period $(\mathrm{t}=0)$.

Fuller et al. (2012) proved that returns from the ex ante efficient portfolio are always inferior to the ex post efficient frontier. This is due to the correction of ex ante mispricing and the arrival of information unavailable and unanticipated by investors at the ex ante stage. This information causes unexpected price changes to create 'winner' and 'loser' shares.

The effect of noise may therefore be estimated as the amount by which the benchmark portfolio is inferior to the ex post efficient frontier. Fuller et al. (2012: 63) provided analytical proof that the PF portfolio lies on the ex post efficient frontier. The amount by which the PF portfolio return exceeds that of the benchmark portfolio is therefore an estimate of the effect of noise on the return of the benchmark portfolio.

Because both the benchmark portfolio and PF portfolio consist of the same shares, only weighted differently, the two portfolios have similar risk characteristics. The excess return $\left(\mathrm{ER}_{\mathrm{y}}\right)$ of the PF portfolio is therefore an indication of the maximum amount of alpha, or ex ante mispricing, available to all investors in a specific segment.

Intuitively, when cross-sectional standard deviation in the market portfolio is high, private information would be more valuable and informed investors would be able to profit more from their information advantage. In fact, cross-sectional dispersion of returns is a required enabler of active management. If there were no dispersion in share returns, active managers would find it impossible to distinguish between 'winner' and 'loser' shares and it would be impossible to beat the benchmark (Gorman, Sapra \& Weigard, 2010). As expected, Fuller et al. (2012) also found a strong positive correlation between PF excess return and cross-sectional standard deviation of share returns.

Fuller et al. (2012) showed that the total PF excess return for the Large Cap US equity market segment, or the 1000 largest US shares based on market value, was on average $7.2 \%$ per year for the period 1951 to 2009 . This can be thought of as the maximum amount of alpha, or ex ante mispricing, available to all investors in the Large Cap US equity market segment.

\section{Data collection}

The calculation of PF excess return required a range of datasets from the JSE and other sources. Index data were required to construct segment portfolios, whilst share prices, dividends, market capitalisation and free float data were required to calculate portfolio weights and returns. In addition, data on corporate actions such as company renames, share splits and consolidations were required to enable accurate return calculations.
For the period June 2002 to December 2014, the JSE provided four data sets containing monthly constituent data for the FTSE/JSE Top 40 (J200), Mid Cap (J201), Small Cap (J202) and All Share (J203) indices. In addition, the JSE provided Peregrine Quants backtrack data listing J203-compatible companies for March 1995 to June 2002.

JSE SENS articles, quarterly index reviews, company websites and Who Owns Whom (2014) provided information on company name changes, listings and delistings. To ensure continuity in annual return calculations, all data for renamed companies were recorded with the latest company name.

For the period 2002 to 2014, the JSE provided free float market capitalisation data for the All Share Index (J203). For the years 1995 to 2002, the JSE provided gross market capitalisation data and the Peregrine Quants backtrack free float data.

Finally, the JSE provided the following data sets for prices, dividends and corporate actions:

- A data set containing all dividends paid in the period January 1995 to December 2014.

- A data set containing All Share splits and consolidations in the period January 1995 to December 2014.

- Data sets containing daily J203 share prices for the period June 2002 to December 2014.

- A data set per year containing daily CI01 (the predecessor of J203) share prices for the period December 1994 to June 2002.

Daily price data were required to capture share prices at delisting.

\section{Research methodology}

Using the methodology of Fuller et al. (2012), PF excess return was calculated as an estimate of the effect of noise on the returns of cap-weighted portfolios in various JSE segments. The measurement period for the calculation of portfolio returns was a calendar year with $t=0$ on 31 December of year 0 and $t=1$ on 31 December of year 1 . It was assumed that both the benchmark and the PF portfolios were buy-and-hold portfolios rebalanced once a year on 31 December. In addition, leverage and short selling were not allowed.

To ensure that the benchmark and PF portfolios contained the same shares, portfolios were constructed using JSE index constituents at $\mathrm{t}=0$. For the years 2003 to 2014, segments were based on FTSE/JSE index constituents on 31 December of year 0. Deriving segment constituents for the period 1995 to 2002, the Peregrine Quants backtrack All Share segment constituents were used.

To find Large Cap, Mid Cap and Small Cap segment constituents, shares from the derived All Share data were grouped into segments. The 40 largest companies were 
allocated to the Large Cap segment, the next 60 to the Mid Cap segment and the remainder to the Small Cap segment.

Transaction costs were ignored and monthly share returns were based on dividends received and capital gain or loss due to price changes. Monthly returns were adjusted to incorporate share splits and consolidations. Companies that delisted during the year were incorporated in the PF portfolio until the last month of delisting in order to eliminate survivorship bias. In addition, monthly returns were winsorised at a $1 \%$ level to remove outliers.

The adjusted market capitalisation of a share is the product of its price and number of free float shares. In a market capweighted portfolio, the weight $\mathrm{w}_{\mathrm{i}}$ assigned to share i's return is its adjusted market capitalisation divided by the total adjusted market capitalisation of the portfolio.

The benchmark portfolio held all shares in the segment with weights proportional to free float market capitalisation at the beginning of the period $(t=0)$ :

$$
\mathrm{w}_{\mathrm{i}, \mathrm{y}, 0}=\frac{\mathrm{p}_{\mathrm{i}, \mathrm{y}, 0} \mathrm{~s}_{\mathrm{i}, \mathrm{y}, 0}}{\sum_{1=1}^{\mathrm{n}} \mathrm{p}_{\mathrm{i}, \mathrm{y}, 0} \mathrm{~s}_{\mathrm{i}, \mathrm{y}, 0}}
$$

where

$$
\begin{aligned}
& \mathrm{w}_{\mathrm{i}, \mathrm{y}, 0}=\text { weight of share } \mathrm{i} \text { at the start }(\mathrm{t}=0) \text { of year } \mathrm{y} \\
& \mathrm{p}_{\mathrm{i}, \mathrm{y}, 0}=\text { price of share } \mathrm{i} \text { at point } \mathrm{t}=0 \text { of year } \mathrm{y} \text {, and } \\
& \mathrm{s}_{\mathrm{i}, \mathrm{y}, 0}=\text { free float shares in issue for share } \mathrm{i} \text { at point } \\
& \mathrm{t}=0 \text { of year } \mathrm{y} \text {. }
\end{aligned}
$$

The PF portfolio, on the other hand, was weighted by ex post market capitalisation:

$$
\mathrm{w}_{\mathrm{i}, \mathrm{y}, 1}=\frac{\mathrm{p}_{\mathrm{i}, \mathrm{y}, 1} \mathrm{~s}_{\mathrm{i}, \mathrm{y}, 1}}{\sum_{1=1}^{\mathrm{n}} \mathrm{p}_{\mathrm{i}, \mathrm{y}, 1} \mathrm{~s}_{\mathrm{i}, \mathrm{y}, 1}}
$$

The realised ex post return of the benchmark portfolio was:

$$
\mathrm{R}_{\mathrm{BP}, \mathrm{y}}=\sum_{\mathrm{i}=1}^{\mathrm{n}} \mathrm{w}_{\mathrm{i}, \mathrm{y}, 0} \cdot \mathrm{R}_{\mathrm{i}, \mathrm{y}}
$$

where

$$
\begin{aligned}
& \mathrm{R}_{\mathrm{BP}, \mathrm{y}}=\text { return for the benchmark portfolio for the } \\
& \text { year } \mathrm{y},
\end{aligned}
$$

and

$\mathrm{R}_{\mathrm{i}}=$ realised annual return for share $\mathrm{i}$ in the period $t=(0-1)$.

The realised ex post return of the PF portfolio was:

$$
\mathrm{R}_{\mathrm{PFP}, \mathrm{y}}=\sum_{\mathrm{i}=1}^{\mathrm{n}} \mathrm{w}_{\mathrm{i}, \mathrm{y}, 1} \cdot \mathrm{R}_{\mathrm{i}, \mathrm{y}}
$$

Using Fuller et al.'s (2012) methodology, the negative effect of noise on the return of the benchmark portfolio was estimated as the amount by which the return of the PF portfolio exceeded that of the benchmark portfolio.

Annual PF excess return was therefore:

$$
\begin{aligned}
& \mathrm{ER}_{\mathrm{y}}=\mathrm{R}_{\mathrm{PFP}, \mathrm{y}}-\mathrm{R}_{\mathrm{BP}, \mathrm{y}} \\
& \mathrm{ER}_{\mathrm{y}}=\sum_{\mathrm{i}=1}^{\mathrm{i}=\mathrm{n}} \quad\left(\mathrm{w}_{\mathrm{i}, \mathrm{y}, 1}-\mathrm{w}_{\mathrm{i}, \mathrm{y}, 0}\right) \mathrm{R}_{\mathrm{i}, \mathrm{y}}
\end{aligned}
$$

where

$$
\begin{gathered}
\mathrm{ER}_{\mathrm{y}}=\quad \text { excess return for the PF portfolio for } \\
\text { investment year } \mathrm{y} .
\end{gathered}
$$

\section{Results}

\section{All share segment results}

Table 1 lists the PF portfolio and benchmark (BP) returns, excess returns and cross-sectional standard deviations of the All Share segment for the years 1995 to 2014. Summary statistics at the bottom of Table 1 show that the standard deviation of annual portfolio returns was $23.06 \%$ for the PF portfolio and $21.41 \%$ for the benchmark portfolio. The correlation of the PF and benchmark portfolio return series was $96.43 \%$ with a beta of 1.04 . The similar risk characteristics are not surprising, because the two portfolios comprised exactly the same shares every year, only weighted differently.

Although PF and/or benchmark portfolio returns may have been negative in some years (1997, 1998, 2000, 2002 and 2008), PF portfolio returns always exceeded benchmark portfolio returns. These results agree with Fuller et al.'s (2012: 52) analytical proof that the benchmark portfolio is an inferior portfolio to the ex post efficient frontier on which the PF portfolio lies.

The PF excess return column was the focus of this study. It shows the amount by which the PF portfolio return exceeded the benchmark portfolio return. Summary statistics at the bottom of Table 1 show that excess return ranged from a low of $2.50 \%$ (2010 and 2011) to a high of $23.53 \%$ (1999), while the annualised average was $8.97 \%$ for the 20 year period 1995 to 2014 . In the last 10 years (2005-2014), PF excess return did not exceed 7\%, except in 2013 when it reached $9.80 \%$.

where

$\mathrm{R}_{\mathrm{PFP}, \mathrm{y}}=$ return for the PF portfolio in year $\mathrm{y}$. 
Table 1: All Share segment benchmark and PF portfolio results

\begin{tabular}{|c|c|c|c|c|c|}
\hline Year & Constituents & $\begin{array}{l}\text { PFP return, } \\
\text { R(PFP) (\%) }\end{array}$ & $\begin{array}{l}\text { BP return, } \\
\mathrm{R}(\mathrm{BP})(\%)\end{array}$ & $\begin{array}{l}\text { PF excess } \\
\text { return (\%) }\end{array}$ & $\begin{array}{c}\text { Cross-sectional } \\
\text { standard deviation (\%) }\end{array}$ \\
\hline 1995 & 95 & 16.69 & 8.61 & 8.08 & 28.93 \\
\hline 1996 & 162 & 13.84 & 5.57 & 8.26 & 31.61 \\
\hline 1997 & 164 & 7.74 & -11.59 & 19.33 & 38.42 \\
\hline 1998 & 164 & 7.69 & -4.64 & 12.33 & 36.88 \\
\hline 1999 & 164 & 85.02 & 61.49 & 23.53 & 69.27 \\
\hline 2000 & 164 & 7.27 & -3.53 & 10.80 & 36.84 \\
\hline 2001 & 164 & 53.94 & 31.33 & 22.61 & 58.18 \\
\hline 2002 & 159 & -0.78 & -10.65 & 9.87 & 35.28 \\
\hline 2003 & 170 & 20.54 & 14.24 & 6.29 & 28.07 \\
\hline 2004 & 162 & 33.62 & 23.49 & 10.13 & 40.06 \\
\hline 2005 & 160 & 50.87 & 45.72 & 5.15 & 26.64 \\
\hline 2006 & 162 & 43.22 & 39.70 & 3.52 & 22.72 \\
\hline 2007 & 164 & 24.00 & 17.06 & 6.95 & 29.92 \\
\hline 2008 & 166 & -20.85 & -27.28 & 6.43 & 21.30 \\
\hline 2009 & 166 & 35.59 & 31.65 & 3.94 & 22.96 \\
\hline 2010 & 163 & 20.67 & 18.17 & 2.50 & 17.69 \\
\hline 2011 & 164 & 4.75 & 2.25 & 2.50 & 16.67 \\
\hline 2012 & 164 & 31.93 & 26.56 & 5.37 & 27.48 \\
\hline 2013 & 164 & 30.72 & 20.92 & 9.80 & 33.44 \\
\hline 2014 & 165 & 15.41 & 10.29 & 5.12 & 23.73 \\
\hline \multirow{11}{*}{ Return } & & $22.12 \%$ & $13.04 \%$ & $8.97 \%$ & \\
\hline & tandard deviation & $23.06 \%$ & $21.41 \%$ & & \\
\hline & \multirow{6}{*}{$\begin{array}{l}\text { Tracking error } \\
\text { Information ratio }\end{array}$} & & & $6.17 \%$ & \\
\hline & & & & 1.48 & \\
\hline & & & High & $23.53 \%$ & $69.27 \%$ \\
\hline & & & Low & $2.50 \%$ & $16.67 \%$ \\
\hline & & & Range & $21.04 \%$ & $52.60 \%$ \\
\hline & & & Average & $9.13 \%$ & $32.30 \%$ \\
\hline & \multicolumn{4}{|c|}{ Correlation of PF portfolio and benchmark returns } & $96.43 \%$ \\
\hline & \multirow{2}{*}{\multicolumn{4}{|c|}{$\begin{array}{r}\text { Beta } \\
\text { Correlation of excess return and cross-sectional standard deviation }\end{array}$}} & 1.04 \\
\hline & & & & & $93.79 \%$ \\
\hline
\end{tabular}

The last column in Table 1 lists year-by-year cross-sectional standard deviation. When comparing the PF excess return column and the cross-sectional standard deviation column, it is clear that the two are highly correlated. Figure 1 illustrates the correlation and summary statistics at the bottom of the Table 1 show a correlation coefficient of $93.79 \%$.

The highly correlated result agrees with Fuller et al.'s (2012:63) analytical proof of positive correlation between cross-sectional standard deviation and excess return. It also agrees with Gorman et al.'s (2010) argument that higher volatility of share returns allows more profit making opportunities for active management.

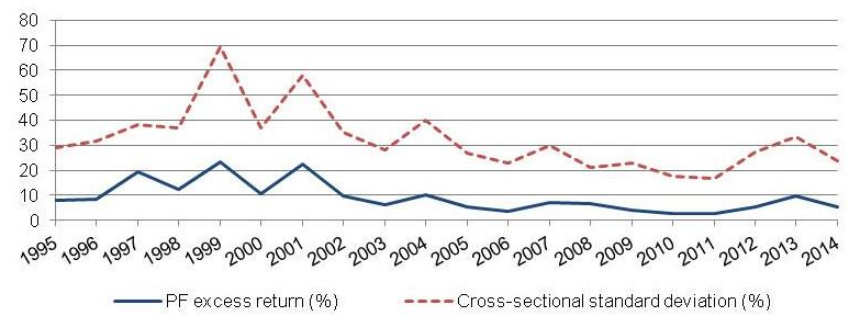

Figure 1: All share segment PF excess return and crosssectional standard deviation

Table 1 summary statistics show that cross-sectional standard deviation was highest in 1999 (69.27\%). Using Gorman et al.'s (2010) argument, 1999 would therefore have provided the most opportunities for active managers to exceed the All Share benchmark return by deviating from ex ante portfolio weights. Information to guide such decision making would have been very valuable and it is not surprising that PF excess return was also highest in 1999 (23.53\%).
Cross-sectional standard deviation and PF excess return were higher and more volatile in the first 10 years than in the next 10. Average cross-sectional standard deviation for the first 10 years (1995-2004) was $40.35 \%$ compared to $24.26 \%$ for the last 10 years (2005-2014). Average PF excess return, in turn, was $12.97 \%$ for the first 10 years compared to $5.11 \%$ for the last 10 years. Table 2 and Figure 2 show the results by five-year periods to illustrate the decline.

Table 2: PF excess return and cross-sectional standard deviation by 5 year period

\begin{tabular}{cccc} 
Period & $\begin{array}{c}\text { Average PF excess } \\
\text { return (\%) }\end{array}$ & $\begin{array}{c}\text { Average cross-sectional } \\
\text { standard deviation (\%) }\end{array}$ & $\begin{array}{c}\text { PF excess return } \\
\text { standard deviation or } \\
\text { tracking error (\%) }\end{array}$ \\
\hline $1995-1999$ & 14.14 & 41.02 & 6.88 \\
$2000-2004$ & 11.81 & 39.69 & 6.22 \\
$2005-2009$ & 5.19 & 24.71 & 1.50 \\
$2010-2014$ & 4.84 & 23.80 & 2.98 \\
\hline Full study period & 8.97 & 32.30 & 6.17
\end{tabular}

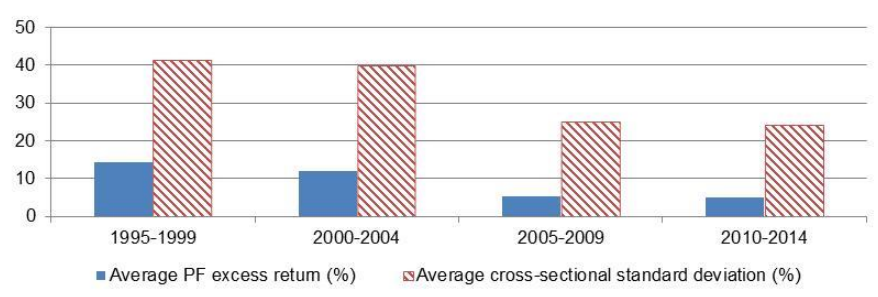

Figure 2: PF excess return and cross-sectional standard deviation by 5 -year period

This decline in average cross-sectional standard deviation corresponds to the results of Raubenheimer (2011), who investigated annual cross-sectional standard deviation in the JSE All Share, Resources, Industrials and Financials segments for the period 1997 to 2009. In addition, it seems to follow the trend found by Fuller et al. (2012) in their study on PF excess return in various equity segments for the period 1973 to 2009 . Their results were by decade, which makes direct comparison to this study difficult, but they also found that cross-sectional standard deviation and excess return were higher in the 1990's than the 2000's.

Although Ankrim and Ding (2002) suggested that a decrease in cross-sectional standard deviation may result from factors such as consolidation, later listing of companies in their life cycle and the influence of day-traders, it is unclear from this study what the causes were. It does however seem that there were more profit making opportunities and higher total potential alpha for All Share investors during the first 10 years than during the last 10 years of the study period.

\section{Large Cap segment results}

Table 3 lists the portfolio returns, PF excess returns and crosssectional standard deviations of the Large Cap segment for the period 1995 to 2014. Summary statistics at the bottom of Table 3 show that cross-sectional standard deviation in the Large Cap segment ranged from a low of $14.55 \%$ in 2010 to a high of $60.87 \%$ in 1999 . PF excess return was lowest in $2010(1.75 \%)$ and highest in $2001(22.04 \%)$. Investors may 
therefore have found 2010 the most difficult year in which to beat the benchmark and 2001 the easiest.

Table 3: Large Cap segment benchmark and PF portfolio results

\begin{tabular}{|c|c|c|c|c|c|}
\hline Year & Constituents & $\begin{array}{l}\text { PFP return, } \\
\mathrm{R}(\mathrm{PFP})(\%)\end{array}$ & $\begin{array}{l}\mathrm{BP} \text { return, } \\
\mathrm{R}(\mathrm{BP})(\%)\end{array}$ & $\begin{array}{l}\mathrm{PF} \text { excess } \\
\text { return }(\%)\end{array}$ & $\begin{array}{c}\text { Cross-sectional } \\
\text { standard deviation (\%) }\end{array}$ \\
\hline 1995 & 40 & 16.53 & 9.34 & 7.19 & 27.90 \\
\hline 1996 & 40 & 11.37 & 5.72 & 5.64 & 28.93 \\
\hline 1997 & 40 & 1.15 & -13.50 & 14.65 & 33.28 \\
\hline 1998 & 44 & 2.81 & -5.39 & 8.19 & 31.82 \\
\hline 1999 & 42 & 90.91 & 70.66 & 20.25 & 60.87 \\
\hline 2000 & 42 & 9.32 & 1.20 & 8.12 & 32.85 \\
\hline 2001 & 42 & 54.82 & 32.77 & 22.04 & 60.54 \\
\hline 2002 & 40 & -5.17 & -13.33 & 8.17 & 29.36 \\
\hline 2003 & 42 & 16.86 & 11.89 & 4.97 & 22.17 \\
\hline 2004 & 41 & 30.27 & 21.57 & 8.70 & 34.41 \\
\hline 2005 & 41 & 51.98 & 47.32 & 4.66 & 25.28 \\
\hline 2006 & 41 & 42.92 & 40.07 & 2.85 & 20.79 \\
\hline 2007 & 41 & 22.15 & 16.18 & 5.97 & 27.92 \\
\hline 2008 & 41 & -22.65 & -28.47 & 5.81 & 20.10 \\
\hline 2009 & 41 & 35.23 & 31.76 & 3.47 & 21.32 \\
\hline 2010 & 41 & 18.03 & 16.28 & 1.75 & 14.55 \\
\hline 2011 & 42 & 4.25 & 1.97 & 2.28 & 15.54 \\
\hline 2012 & 42 & 30.46 & 25.40 & 5.06 & 26.81 \\
\hline 2013 & 42 & 32.40 & 22.38 & 10.02 & 34.07 \\
\hline 2014 & 42 & 12.49 & 8.45 & 4.04 & 20.96 \\
\hline \multirow{11}{*}{ Return } & & $20.52 \%$ & $12.94 \%$ & $7.57 \%$ & \\
\hline & andard deviation & $24.98 \%$ & $22.97 \%$ & & \\
\hline & Tracking error & & & $5.49 \%$ & \\
\hline & \multirow[t]{5}{*}{ Information ratio } & & & 1.40 & \\
\hline & & & High & $22.04 \%$ & $60.87 \%$ \\
\hline & & & Low & $1.75 \%$ & $14.55 \%$ \\
\hline & & & Range & $20.29 \%$ & $46.33 \%$ \\
\hline & & & Average & $7.69 \%$ & $29.47 \%$ \\
\hline & \multicolumn{4}{|c|}{ Correlation of PF portfolio and benchmark returns } & $97.73 \%$ \\
\hline & \multirow{2}{*}{\multicolumn{4}{|c|}{$\begin{array}{r}\text { Beta } \\
\text { Correlation of excess return and cross-sectional standard deviation }\end{array}$}} & 1.06 \\
\hline & & & & & $95.69 \%$ \\
\hline
\end{tabular}

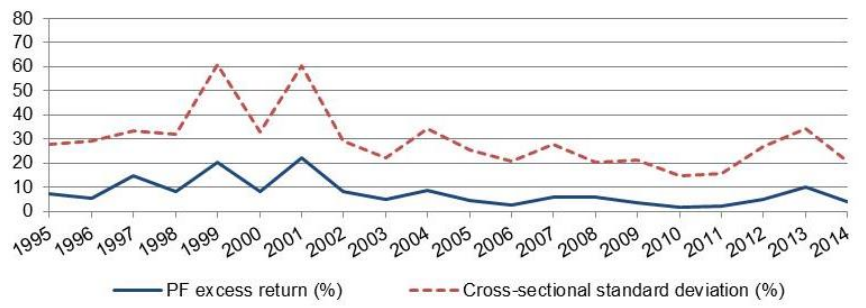

Figure 3: Large Cap segment PF excess return and cross-sectional standard deviation

Figure 3 illustrates the volatility of cross-sectional standard deviation and PF excess return for the Large Cap segment. Similar to the All Share segment, there was a strong correlation (95.69\%) between cross-sectional standard deviation and PF excess return. For the first 10 years (1995-2004), average cross-sectional standard deviation was $36.21 \%$ and excess return $10.65 \%$. For last 10 years (20052014), average cross-sectional standard deviation was $22.73 \%$ and excess return $4.57 \%$. Again, results were lower in the last 10 years and investors may have found it more difficult to beat the Large Cap benchmark in the last 10 years than in the first 10 .

Not only were results higher in the first 10 years, but they were also more volatile. Table 3 summary statistics show a $5.49 \%$ tracking error for the period 1995 to 2014. The volatility of PF excess return was higher in the first 10 years with a tracking error of $6.05 \%$ for the period 1995 to 2004 , compared to $2.38 \%$ for the 10 years 2005 to 2014 .
By comparing Figure 3 with Figure 1, one can see that the Large Cap segment consistently had lower cross-sectional standard deviation and PF excess return than the All Share segment.

Summary statistics at the bottom of Table 3 and Table 1 also show that average cross-sectional standard deviation was lower for the Large Cap segment (29.47\%) than the All Share segment $(32.30 \%)$. As expected, average annual PF excess return was also lower for the Large Cap segment (7.57\%) than the All Share segment (8.97\%). If PF excess return is an accepted estimate of the maximum potential alpha available to all investors in the segment, the lower annualised excess return for the Large Cap segment suggests that it may have been more difficult for active managers to outperform the Large Cap benchmark than the All Share benchmark.

\section{Mid Cap segment results}

Table 4 lists the portfolio returns, excess returns and crosssectional standard deviations for the Mid Cap segment. Summary statistics at the bottom of Table 4 show that crosssectional standard deviation in the Mid Cap segment ranged from a low of $20.43 \%$ in 2011 to a high of $63.43 \%$ in 1999 . PF excess return was also highest in 1999 (28.58\%) and lowest in $2011(2.97 \%)$. Investors may therefore have found 1999 the easiest year in which to beat the benchmark and 2011 the most difficult.

Table 4: Mid Cap segment benchmark and PF portfolio results

\begin{tabular}{|c|c|c|c|c|c|}
\hline Year & Constituents & $\begin{array}{l}\text { PFP return, } \\
\text { R(PFP) (\%) }\end{array}$ & $\begin{array}{l}\text { BP return, } \\
\text { R(BP) (\%) }\end{array}$ & $\begin{array}{l}\text { PF excess } \\
\text { return (\%) }\end{array}$ & $\begin{array}{c}\text { Cross-sectional } \\
\text { standard deviation (\%) }\end{array}$ \\
\hline 1995 & 55 & 17.94 & 3.38 & 14.56 & 37.16 \\
\hline 1996 & 60 & 21.21 & 6.90 & 14.31 & 37.54 \\
\hline 1997 & 64 & 20.12 & -7.78 & 27.90 & 46.02 \\
\hline 1998 & 60 & 14.45 & -2.08 & 16.53 & 41.53 \\
\hline 1999 & 62 & 66.05 & 37.47 & 28.58 & 63.43 \\
\hline 2000 & 62 & -15.70 & -31.92 & 16.22 & 32.03 \\
\hline 2001 & 62 & 46.68 & 21.00 & 25.68 & 50.53 \\
\hline 2002 & 59 & 31.49 & 15.96 & 15.52 & 39.28 \\
\hline 2003 & 63 & 41.09 & 28.84 & 12.25 & 39.44 \\
\hline 2004 & 61 & 50.72 & 34.05 & 16.67 & 46.88 \\
\hline 2005 & 59 & 40.43 & 34.35 & 6.08 & 27.61 \\
\hline 2006 & 63 & 43.73 & 36.88 & 6.85 & 31.63 \\
\hline 2007 & 63 & 32.34 & 20.64 & 11.70 & 38.59 \\
\hline 2008 & 63 & -8.92 & -17.64 & 8.72 & 27.47 \\
\hline 2009 & 63 & 38.91 & 32.63 & 6.28 & 27.96 \\
\hline 2010 & 62 & 34.75 & 30.61 & 4.15 & 24.38 \\
\hline 2011 & 61 & 7.06 & 4.08 & 2.97 & 20.43 \\
\hline 2012 & 61 & 39.38 & 33.01 & 6.37 & 32.06 \\
\hline 2013 & 61 & 19.88 & 11.81 & 8.07 & 31.30 \\
\hline 2014 & 61 & 29.58 & 20.77 & 8.81 & 33.00 \\
\hline \multirow{11}{*}{ Return } & & $27.00 \%$ & $13.85 \%$ & $12.68 \%$ & \\
\hline & tandard deviation & $19.71 \%$ & $19.59 \%$ & & \\
\hline & \multirow{6}{*}{$\begin{array}{l}\text { Tracking error } \\
\text { Information ratio }\end{array}$} & & & $7.57 \%$ & \\
\hline & & & & 1.71 & \\
\hline & & & High & $28.58 \%$ & $63.43 \%$ \\
\hline & & & Low & $2.97 \%$ & $20.43 \%$ \\
\hline & & & Range & $25.61 \%$ & $43.00 \%$ \\
\hline & & & Average & $12.91 \%$ & $36.41 \%$ \\
\hline & & \multirow{2}{*}{\multicolumn{3}{|c|}{$\begin{array}{r}\text { Correlation of PF portfolio and benchmark returns } \\
\text { Beta }\end{array}$}} & $92.58 \%$ \\
\hline & & & & & 0.93 \\
\hline & Correlation of exce & ss return and $\mathrm{cr}$ & $s$-sectional sta & deviation & $90.93 \%$ \\
\hline
\end{tabular}




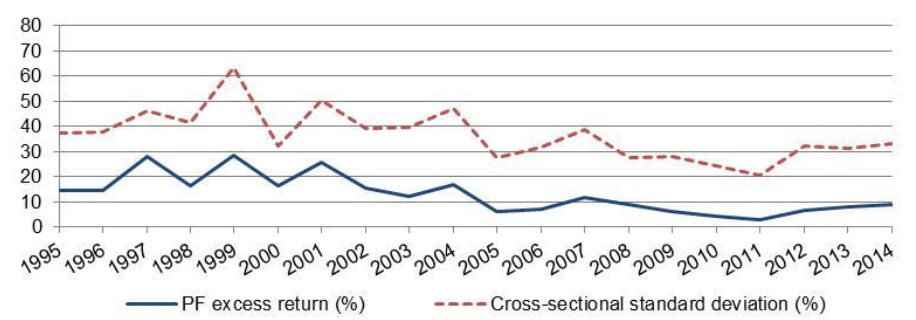

Figure 4: Mid Cap segment PF excess return and crosssectional standard deviation

Figure 4 illustrates the volatility of cross-sectional standard deviation and PF excess return for the Mid Cap segment. Similar to the All Share and Large Cap segments, there was a strong correlation $(90.93 \%)$ between cross-sectional standard deviation and PF excess return. For the first 10 years (19952004), average cross-sectional standard deviation was $43.38 \%$ and excess return $18.69 \%$. For the last 10 years (2005-2014), average cross-sectional standard deviation was $29.44 \%$ and excess return $6.97 \%$. Again, results were lower in the last 10 years and investors may have found it more difficult to beat the Mid Cap benchmark in the last 10 years than in the first 10 .

When comparing Figure 4 with Figures 1 and 3 it is apparent that the Mid Cap segment consistently had both higher crosssectional standard deviation and higher PF excess return than the All Share and Large Cap segments during the full 20-year period (1995-2014).

Summary statistics at the bottom of Tables 1 to 4 also show that average cross-sectional standard deviation was higher for the Mid Cap (36.41\%) than the Large Cap (29.47\%) and All Share (32.30\%) segments. Average annual PF excess return was also higher for the Mid Cap (12.68\%) than the Large Cap (7.57\%) and All Share segments (8.97\%). This result suggests that it may have been easier for active managers to outperform the Mid Cap benchmark than the All Share and Large Cap benchmarks.

\section{Small Cap segment results}

Table 5 lists the results for the Small Cap segment. Summary statistics show that cross-sectional standard deviation in the segment ranged from $21.62 \%$ in 2008 to $70.58 \%$ in 1998. PF excess return was highest in $1998(41.91 \%)$ and lowest in $2013(5.61 \%)$. The 1998 benchmark may therefore have been easier to beat than the 2013 one.
Table 5: Small cap segment benchmark and PF portfolio results

\begin{tabular}{|c|c|c|c|c|c|}
\hline Year & Constituents & $\begin{array}{l}\text { PFP return, } \\
\text { R(PFP) (\%) }\end{array}$ & $\begin{array}{l}\text { BP return, } \\
\text { R(BP) (\%) }\end{array}$ & $\begin{array}{l}\text { PF excess } \\
\text { return (\%) }\end{array}$ & $\begin{array}{c}\text { Cross-sectional } \\
\text { standard deviation (\%) }\end{array}$ \\
\hline \multicolumn{6}{|l|}{1995} \\
\hline 1996 & 62 & 19.45 & 0.89 & 18.56 & 42.75 \\
\hline 1997 & 60 & 43.45 & 4.76 & 38.69 & 60.33 \\
\hline 1998 & 60 & 38.87 & -3.04 & 41.91 & 70.58 \\
\hline 1999 & 60 & 38.81 & 9.95 & 28.86 & 54.57 \\
\hline 2000 & 60 & 9.99 & -22.73 & 32.72 & 48.82 \\
\hline 2001 & 60 & 43.83 & 11.86 & 31.97 & 58.38 \\
\hline 2002 & 60 & 20.25 & 6.98 & 13.27 & 39.53 \\
\hline 2003 & 65 & 51.25 & 38.61 & 12.64 & 42.44 \\
\hline 2004 & 60 & 59.55 & 44.09 & 15.46 & 49.73 \\
\hline 2005 & 60 & 57.68 & 44.69 & 12.98 & 40.69 \\
\hline 2006 & 58 & 51.28 & 39.63 & 11.66 & 37.24 \\
\hline 2007 & 60 & 44.76 & 30.50 & 14.26 & 43.51 \\
\hline 2008 & 62 & -22.98 & -29.50 & 6.52 & 21.62 \\
\hline 2009 & 62 & 30.00 & 22.19 & 7.81 & 35.34 \\
\hline 2010 & 60 & 28.83 & 19.24 & 9.59 & 37.06 \\
\hline 2011 & 61 & 8.65 & 1.63 & 7.02 & 30.30 \\
\hline 2012 & 61 & 36.20 & 28.23 & 7.97 & 33.15 \\
\hline 2013 & 61 & 30.92 & 25.31 & 5.61 & 28.85 \\
\hline 2014 & 62 & 25.26 & 15.75 & 9.51 & 33.25 \\
\hline \multirow{11}{*}{ Returr } & & $30.78 \%$ & $13.26 \%$ & $16.70 \%$ & \\
\hline & standard deviation & $19.88 \%$ & $20.81 \%$ & & \\
\hline & Tracking error & & & $11.57 \%$ & \\
\hline & Information ratio & & & 1.49 & \\
\hline & & & High & $41.91 \%$ & $70.58 \%$ \\
\hline & & & Low & $5.61 \%$ & $21.62 \%$ \\
\hline & & & Range & $36.31 \%$ & $48.97 \%$ \\
\hline & & & Average & $17.21 \%$ & $42.53 \%$ \\
\hline & & \multicolumn{3}{|c|}{ Correlation of PF portfolio and benchmark returns } & \\
\hline & & & & Beta & 0.80 \\
\hline & Correlation of ex & eturn and & onal & deviation & $93.03 \%$ \\
\hline
\end{tabular}

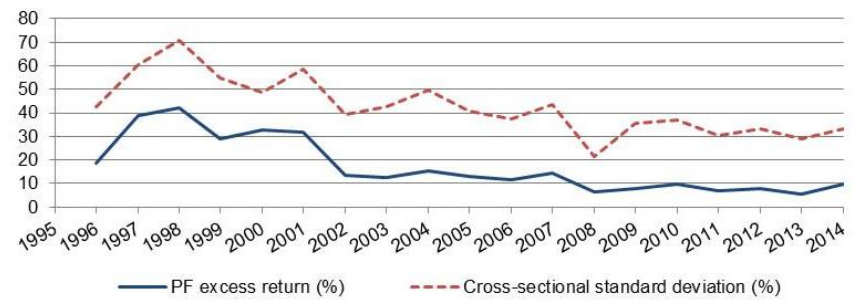

Figure 5: Small cap segment PF excess return and crosssectional standard deviation

Figure 5 illustrates the volatility of cross-sectional standard deviation and PF excess return for the Small Cap segment. Similar to the other segments, there was a strong correlation (93.03\%) between cross-sectional standard deviation and PF excess return. In the first 10 years (1995-2004), average cross-sectional standard deviation was $51.90 \%$ and PF excess return $25.56 \%$. For the last 10 years (2005-2014), average cross-sectional standard deviation was $34.10 \%$ and excess return $9.26 \%$. The lower results suggest that investors may have found it more difficult to beat the Small Cap benchmark in the last 10 years than in the first 10 .

When comparing Figure 5 with Figures 1 to 4 it is apparent that the Small Cap segment consistently had the highest cross-sectional standard deviation and PF excess return for all segments during the full 20-year period 1995 to 2014. Summary statistics at the bottom of Tables 1 to 5 also show that average cross-sectional standard deviation was higher for the Small Cap (42.53\%) than the Large Cap (29.47\%), All Share $(32.30 \%)$ and Mid Cap (36.41\%) segments. Average annual PF excess return was also higher for the Small Cap (16.70\%) than the Large Cap (7.57\%), All Share (8.97\%) and Mid Cap (12.68\%) segments. This result suggests that the Small Cap segment offered the most opportunities for active 
management and had the highest potential alpha for all investors. Active managers in the Small Cap segment may therefore have consistently found it the easiest segment in which to outperform the benchmark.

\section{Conclusion}

Table 6 summarises the results across segments. Average annual cross-sectional standard deviation and PF excess return were lowest in the Large Cap segment $(29.47 \%$ and $7.57 \%$ respectively) and highest in the Small Cap segment (42.53\% and $16.70 \%$ respectively). According to Gorman et al. (2010), the high cross-sectional standard deviation in the Small Cap segment suggests that it offered the most opportunities for active management, whilst the Large Cap segment offered the least.

Table 6: Summary statistics for various JSE segments, 1995-2014

\begin{tabular}{rcccc} 
Segment & $\begin{array}{c}\text { Average PF } \\
\text { excess } \\
\text { return (\%) }\end{array}$ & $\begin{array}{c}\text { Average cross-sectional } \\
\text { standard deviation (\%) }\end{array}$ & $\begin{array}{c}\text { Correlation of PF excess } \\
\text { return and cross-sectional } \\
\text { standard deviation (\%) }\end{array}$ & $\begin{array}{c}\text { Average } \\
\text { market cap } \\
\text { (R billion) }\end{array}$ \\
\cline { 1 - 1 } Headline Indices & & & & \\
\cline { 2 - 2 } All Share & 8.97 & 32.30 & 93.79 & 14.84 \\
Large Cap & 7.57 & 29.47 & 95.69 & 48.74 \\
Mid Cap & 12.68 & 36.41 & 90.93 & 4.92 \\
Small Cap & 16.70 & 42.53 & 93.03 & 1.07
\end{tabular}

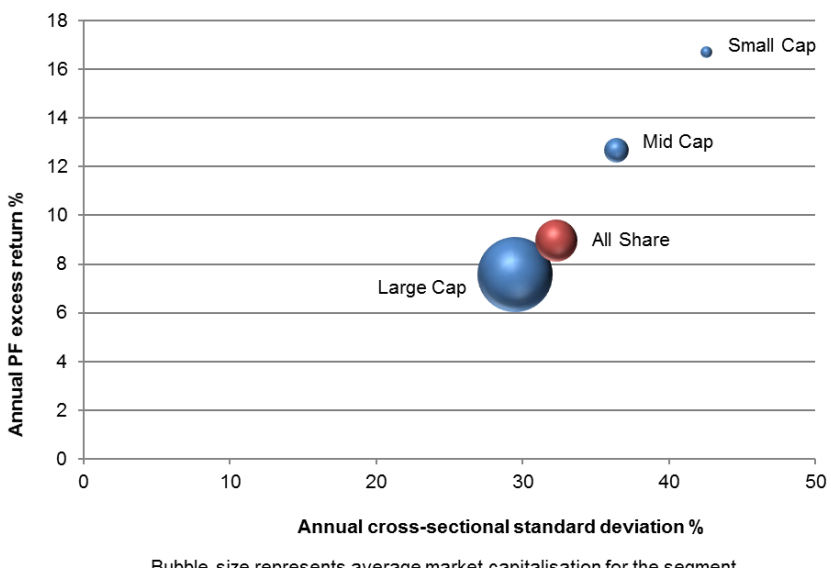

Figure 6: PF excess return and cross-sectional standard deviation for the headline segments

Figure 6 graphically illustrates the results for the different segments. The strong correlation between excess return and cross-sectional standard deviation is apparent. All segments had a strong correlation, greater than $90 \%$, between excess return and cross-sectional standard deviation.

In general, the smaller the average company market capitalisation in a segment, the higher the cross-sectional standard deviation of the segment and the greater the positive impact of price changes on the returns of cap-weighted market portfolios. The bubble size in Figure 6 represents average company market capitalisation in the segment as at 31 December 2014 and the general trend of larger excess return for smaller average market capitalisation is clear. The
Small Cap segment had by far the greatest cross-sectional standard deviation and was most severely affected by unexpected price changes as estimated by the PF excess return.

\section{Limitations and Recommendations}

These results should however be approached with some caution. PF excess return is just an estimate of the maximum potential alpha amount across all investors in the segment. Because the results are based on cap-weighted segments, it is possible for investors to achieve higher returns by owning more risky concentrated portfolios consisting of selected shares instead of all index constituents.

In addition, much of the price changes and PF excess returns are due to the arrival of information that is not available and not anticipated at the beginning of the investment period. It is highly unlikely that any investor will ever have 'perfect foresight' as defined in this study.

Finally, whilst the risk characteristics of the PF portfolio and benchmark portfolios are the same, they are not identical. The PF excess return is therefore an estimated ex post return rather than a precise one. This implies that the PF excess return is an estimate of the 'valuation efficiency' of the market or the amount of ex ante mispricing relative to the ex post efficient frontier.

This study covered 20 years, which is a short period on which to base results. The main obstacle to extending the study period beyond 20 years was the availability of All Share and free float data. If estimates of PF excess return prove useful, future researchers should consider investigating a longer period.

Section 4 showed that average cross-sectional standard deviation and PF excess return were higher in the first 10 years than the last 10 years. Although it was outside the scope of this study to investigate the reasons for the decrease in results, it may be useful to understand because it affects opportunities for active management.

Finally, an increase in the number of index funds and ETF's tracking different JSE indices may make it useful to extend the investigation of cross-sectional standard deviation and $\mathrm{PF}$ excess return to other JSE segments.

\section{References}

Ankrim, E. M. \& Ding, Z. 2002. 'Cross-sectional volatility and return dispersion', Financial Analysts Journal, 58(5): 6773.

Arnott, R.D., Li, F. \& Sherrerd, K. F. 2009. 'Clairvoyant value and the value effect', The Journal of Portfolio Management, 35(3): 14-26.

Black, F. 1986. 'Noise', The Journal of Finance, XLI(3): 529-543. 
Campbell, J.Y. \& Kyle, A.S. 1993. 'Smart money, noise trading and stock price behaviour', The Review of Economic Studies, 60(1): 1-34.

De Long, B.J., Shleifer, A., Summers, L.H. \& Waldmann, R.J. 1990. 'Noise trader risk in financial markets', Journal of Political Economy, 98(4): 703-738.

Fama, E.F. 1965. 'Random walks in stock market prices', Financial Analysts Journal, 21(5): 55-59.

Fuller, R.J., Han, B. \& Tung, Y. 2012. 'Estimating the negative impact of noise on the returns of cap-weighted portfolios in various segments of the equity markets', Journal of Investment Management, 10(3): 49-74.

Gorman, L.R., Sapra, S.G. \& Weigand, R.A. 2010. 'The role of cross-sectional dispersion in active portfolio management', Investment Management and Financial Innovations, 7(3): 5858 .

LeRoy, S.F. \& LaCivita, C.J. 1981. 'Risk aversion and the dispersion of asset prices', Journal of Business, 54(4): 535547.

Lewellen, W.G., Schlarbaum, G.E. \& Lease, R.C. 1974. 'The individual investor: Attributes and attitudes', The Journal of Finance, 29(2): 413-33.

Raubenheimer, H. 2011. 'Varying cross-sectional volatility in the South African equity market and the implications for the management of fund managers', South African Journal of Business Management, 42(2): 15-25.

Shiller, R.J. 1979. 'The volatility of long-term interest rates and expectation models of the term structure', The Journal of Political Economy, 87(6): 1190-1219.

Shiller, R.J. 1981. 'Do share prices move too much to be justified by subsequent changes in dividends?', The American Economic Review, 71(3): 421-436.

Shiller, R.J., Fischer, S. \& Friedman, B.M. 1984. 'Stock prices and social dynamics', Brookings Papers on Economic Activity, 1984(2): 457-510. 